\title{
Three-dimensional reconstruction facilitates thoracoscopic anatomical partial lobectomy by an inexperienced surgeon: a single-institution retrospective review
}

\author{
Yun Liu ${ }^{1,2}$, Songlin Zhang ${ }^{1,2}$, Chaobing Liu ${ }^{1,2}$, Lailong Sun ${ }^{1,2}$, Ming Yan $^{1,2}$ \\ ${ }^{1}$ Department of Cardiothoracic Surgery, The First College of Clinical Medical Science, China Three Gorges University, Yichang, China; \\ ${ }^{2}$ Department of Cardiothoracic Surgery, Yichang Central People's Hospital, Yichang, China \\ Contributions: (I) Conception and design: Y Liu; (II) Administrative support: S Zhang; (III) Provision of study materials or patients: Y Liu, S Zhang; \\ (IV) Collection and assembly of data: Y Liu, S Zhang; (V) Data analysis and interpretation: Y Liu; (VI) Manuscript writing: All authors; (VII) Final \\ approval of manuscript: All authors. \\ Correspondence to: Songlin Zhang, MD. Department of Cardiothoracic Surgery, The First College of Clinical Medical Science, China Three Gorges \\ University, Yichang, China; Department of Cardiothoracic Surgery, Yichang Central People's Hospital, No. 183 Yiling Road, Yichang 443000, China. \\ Email: 278087836@qq.com.
}

Background: This study aimed to evaluate the effect of three-dimensional (3D) interactive quantitative surgical planning on the outcome of video-assisted thoracoscopic surgery (VATS) anatomical partial lobectomy (APL), and to investigate the learning curve of 3D reconstruction-assisted VATS APL assisted.

Methods: We retrospectively analyzed 156 cases of solitary pulmonary ground-glass opacity (GGO) lesions in patients who underwent 3D interactive quantitative VATS APL. Digital imaging and communications in medicine data were recorded for each patient. We used Materialise 3-Matic software to make 3D reconstructed images. All surgeries were performed by the same thoracic surgeon at the Cardiothoracic Surgery Department of Yichang Central People's Hospital between February 28, 2018, and April 20, 2020. The learning curve was evaluated using operative time and the cumulative sum (CUSUM) value of operative time in all cases.

Results: VATS APL was performed in every patient successfully, and there were no conversions to thoracotomy or lobectomy. The median surgical margin distance was 2.2 (range, 2.0-2.8) cm. All patients had an R0 complete cancer resection on histology. The histological subtypes of the segmental lesions included 69 cases of minimally invasive adenocarcinoma (MIA), 61 cases of adenocarcinoma, one case of squamous cell carcinoma, 16 cases of adenocarcinoma in situ (AIS), and nine cases of atypical adenomatous hyperplasia (AAH). The median operation time was 119 (range, 57-245) min, and median intraoperative blood loss was 37 (range, 15-247) mL. The median duration of thoracic drainage tube insertion was 2.3 (range, 1-23) days after surgery. The median length of postoperative hospital stay was 3.7 (range, 3-25) days. There were no cases of perioperative death. During the median postoperative follow-up period of 11 (range, 2-26) months, no tumor recurrence or postoperative death was observed. 3D interactive quantitative surgical planning facilitates safe and efficient VATS APL with a learning curve of 30 cases.

Conclusions: 3D interactive quantitative surgical planning for VATS APL is a feasible option for inexperienced surgeons, with acceptable safety and complications.

Keywords: Anatomical partial lobectomy (APL); surgical planning; three-dimensional (3D); video-assisted thoracoscopic surgery (VATS)

Submitted Aug 26, 2021. Accepted for publication Oct 16, 2021.

doi: $10.21037 /$ jtd-21-1578

View this article at: https://dx.doi.org/10.21037/jtd-21-1578 


\section{Introduction}

Owing to the widespread application of high-resolution computed tomography (HRCT) for health examinations in recent years, an increasing number of ground-glass opacity (GGO) lesions have been identified. For these lesions, particularly those with diameters of $<2 \mathrm{~cm}$ and a consolidation ratio of $<50 \%$, lobectomy results in a greater loss of lung function. Numerous clinical studies have shown that there is no significant difference between segmentectomy and lobectomy in the treatment of early small focus lung cancer (1-4). Anatomical partial lobectomy (APL) is based on the anatomy of pulmonary segments and subsegments (5). The APL procedure comprehensively takes into account the individualized surgical differences of sublobectomy in different patients based on the tumor location. For patients with multiple pulmonary nodules, the advantages of APL are more obvious (6). These advantages have resulted in increased interest from both doctors and patients.

The National Comprehensive Cancer Network guidelines clearly states that, the indication for sublobar resection is a lesion around the lung with a diameter of $\leq 2 \mathrm{~cm}$ and with at least one of the following: pathologically confirmed adenocarcinoma in situ (AIS), nodule with $\geq 50 \%$ GGO on CT, and imaging-confirmed tumor doubling time of $\geq 400$ days (7). Thoracoscopic APL is a very delicate technological procedure, and APL is technically more difficult than lobectomy. Anatomic complexity and many variations of segmental bronchi and vessels are other considerations (8). In three-dimensional (3D) reconstruction images, the intersegmental vein and its branches can be accurately identified, allowing the intersegmental plane to be easily recognized. $3 \mathrm{D}$ reconstruction is conducive to identify the lung segment structure, facilitate the localization of lung nodules and the determination of cutting plane (9-11), 3D digital anatomy models are useful in training inexperienced surgeons (12).

The objective of this study was to evaluate the effect of inexperienced surgeon perform $3 \mathrm{D}$ interactive quantitative surgical planning on the outcome of video-assisted thoracoscopic surgery (VATS) APL, and investigate the learning curve of inexperienced surgeon perform VATS APL with $3 \mathrm{D}$ reconstruction. We present the following article in accordance with the STROBE reporting checklist (available at https://dx.doi.org/10.21037/jtd-21-1578).

\section{Methods}

\section{Patients and methods}

A total of 156 patients underwent $3 \mathrm{D}$ interactive quantitative planned VATS APL at the Cardiothoracic Surgery Department of Yichang Central People's Hospital between February 28, 2018, and April 20, 2020. All surgeries were performed by the same thoracic surgeon (Dr. Yun Liu) with assistant surgeons. The inclusion criterion for VATS APL in the present study was CT indicating a single lesion around the lung (considered 1/3 outside the lung parenchyma) with a diameter of $\leq 2 \mathrm{~cm}$ and with at least one of the following: pathologically confirmed AIS, nodule with $\geq 50 \%$ GGO on CT, and imaging-confirmed tumor doubling time of $\geq 400$ days. The preoperative workup of all patients included clinical history, physical examination, thinslice CT of the chest, and routine preoperative examination. Brain magnetic resonance imaging, bone scintigraphy, or positron emission tomography/CT was also performed if necessary. All enrolled patients provided informed consent. The operation time, intraoperative blood loss, resection margin distance, postoperative complications, thoracic tube retention for drainage, length of postoperative hospital stay, and postoperative complications were analyzed, these data are relevant because of the clear statistical methodology and objective determination of the learning curve. The learning curve was analyzed using the cumulative sum (CUSUM) method. The learning curve was evaluated using operative time and the CUSUM value of operative time in all cases. The study was conducted in accordance with the Declaration of Helsinki (as revised in 2013). The protocol of this study was approved by the institutional review board of Yichang Central People's Hospital (No. HECKYJJ-2018-601-01). Informed consent was obtained from the patients before surgery.

\section{D interactive quantitative surgical planning}

All patients underwent preoperative chest thin-slice CT with a slice thickness of $0.625-1.5 \mathrm{~mm}$. Digital imaging and communications in medicine data were recorded for each patient. 3D reconstruction images were generated for all patients using the Materialise 3-Matic software (developed by Materialise Nv Co., Materialise's interactive medical image control system, Belgium; serial number: A51D56D6-C3XE-0011-1F7605D216DF39D5). The 


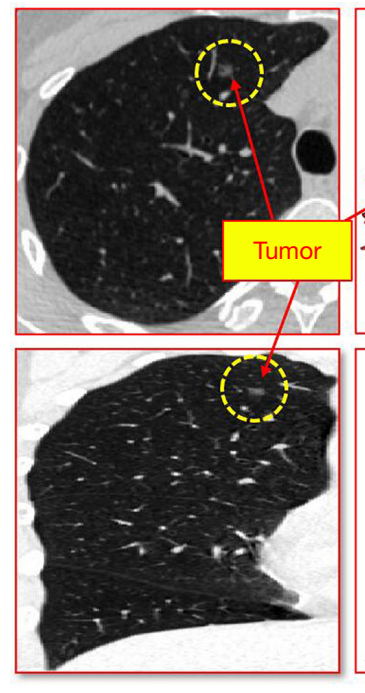

$2 \mathrm{D}$

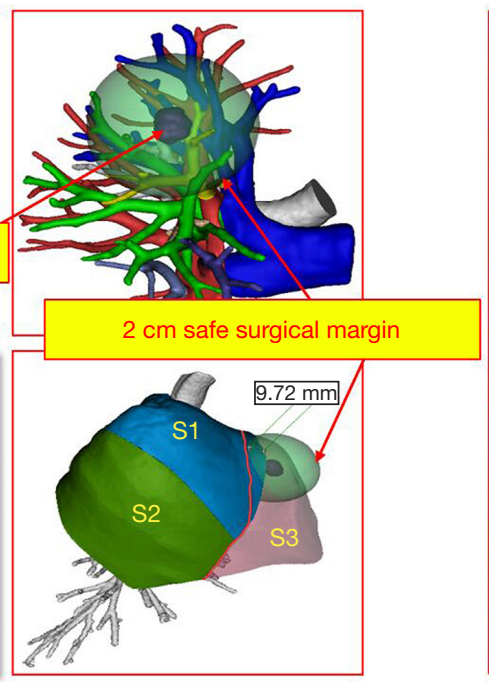

$3 \mathrm{D}$

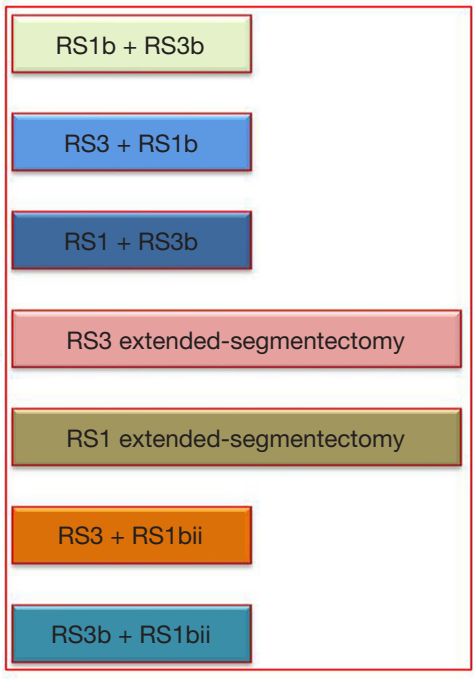

How to do?

Figure 1 According to each specific situation, we selected the most reasonable operation type and planned the surgical path. 2D, twodimensional; 3D, three-dimensional; S1, apical segment; S2, posterior segment; S3, anterior segment.

pulmonary arteries, pulmonary veins, bronchi, and each pulmonary segment were reconstructed and marked with different colours. Accurate determination of the location of pulmonary nodules and $2 \mathrm{~cm}$ safe margin was conducted. The lung tissue involved in the safe resection margin was considered the target segment, and the corresponding segmentectomies were performed accordingly. The anatomic relationship between the nodule and adjacent structures was determined to design an appropriate surgical excision. According to each specific situation, we selected the most reasonable operation type and planned the surgical path (Figure 1).

\section{VATS APL procedure}

General anesthesia, double lumen endotracheal tube placement, and single lung ventilation were used. The patient was placed in the contralateral decubitus position. The surgeon stood at the dorsal side of the patient, with the assistant standing at the ventral side of the patient. Surgery was performed with the lung collapsed on the operating side. VATS APL was performed in all patients via a threeport approach. The thoracoscope port was placed along the midaxillary line of the $8^{\text {th }}$ intercostal space and was approximately $1.5 \mathrm{~cm}$ in length. The main utility incision was made in the $4^{\text {th }}$ or $5^{\text {th }}$ intercostal space along the anterior axillary line and was approximately $3 \mathrm{~cm}$ in length. The assistant incision was made in the $5^{\text {th }}$ intercostal space along the posterior axillary line and was approximately $1.5 \mathrm{~cm}$ in length. The incisions were protected with a silicone rubber wound protector.

Thoracoscopic APL for basal segment or subsegment is technically challenging because of the variation and deep location of vessels and bronchi in the parenchyma (13). We have already described the detailed procedures of right S9+10 segmentectomy in previous reports (14). According to the 3D image, we determined the bronchus and vessels of the target segment, which must be dissected during the operation. We then divided the target segmental bronchus and vessels such as for right $\mathrm{S} 9+10$ segmentectomy (Figure 2). The last step was to manage the intersegmental plane and divide the lung parenchyma. The inflationdeflation method was performed to identify the intersegmental plane, and the contour of the target segment was displayed. Next, a 3D stapler was used for skin closure. Using 3D reconstruction, we could make accurate plans preoperatively, remove the least amount of lung tissue, and retain more lung tissue on the premise of ensuring the safe margin. For example, in procedures such as RS1b subsegmentectomy (Figure 3), we only lost $21.43 \%$ of the right upper lung function, but achieved the same operation effect as a right upper lobectomy, and retained $78.57 \%$ of the right upper lung function.

Upon completion of APL, the lung tissue of the target 

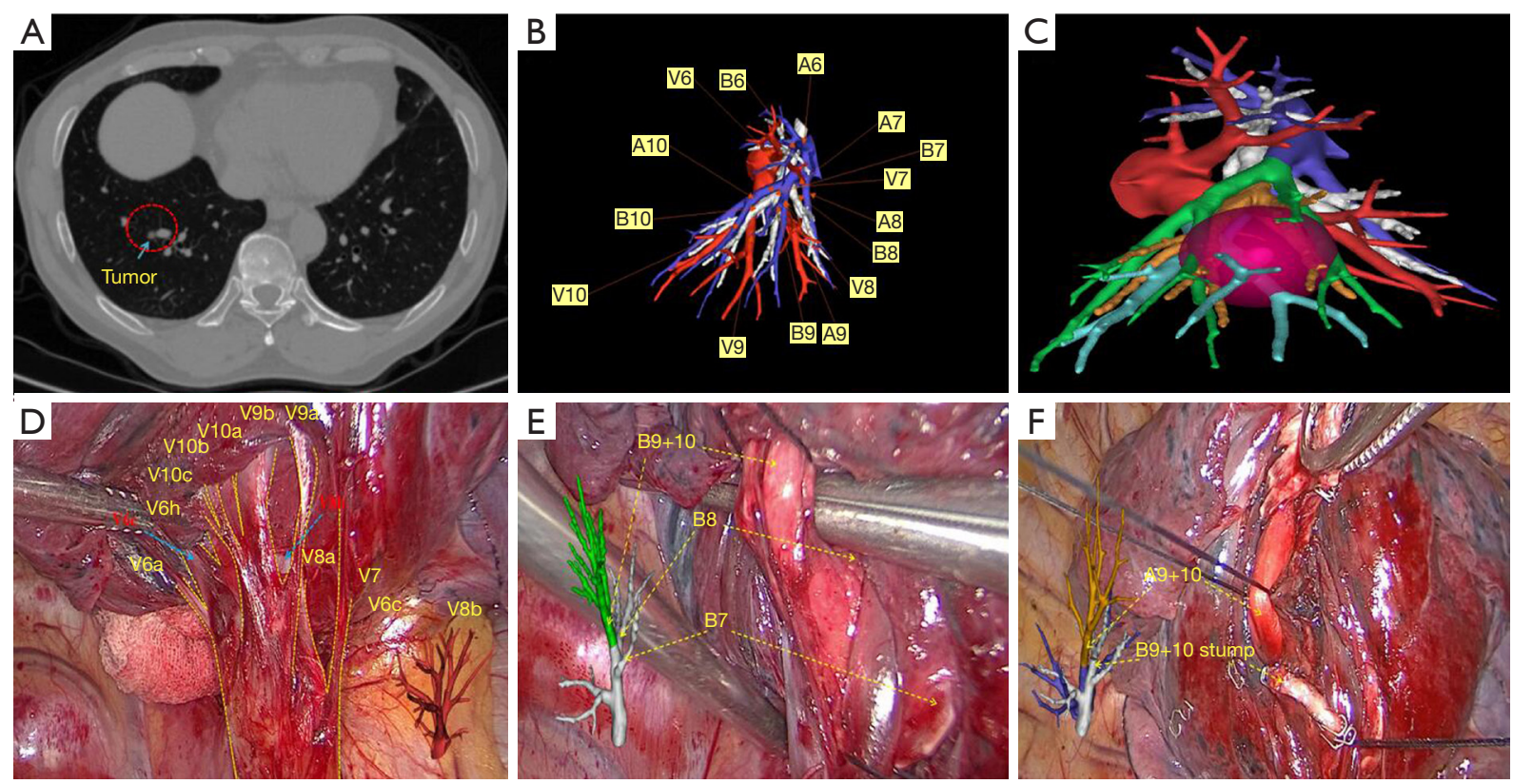

Figure 2 3D interactive quantitative surgical planning VATS right S9+10 segmentectomy. (A) An 8-mm mixed GGO nodule at the basal segments of the right lower lobe; (B) anatomy of the right basal segment; (C) $2 \mathrm{~cm}$ safe resection margin; (D) management of the inferior pulmonary vein; (E) management of the bronchus; and (F) management of the artery. 3D, three-dimensional; VATS, video-assisted thoracoscopic surgery; GGO, ground-glass opacity; V, vein; A, artery; B, bronchus.
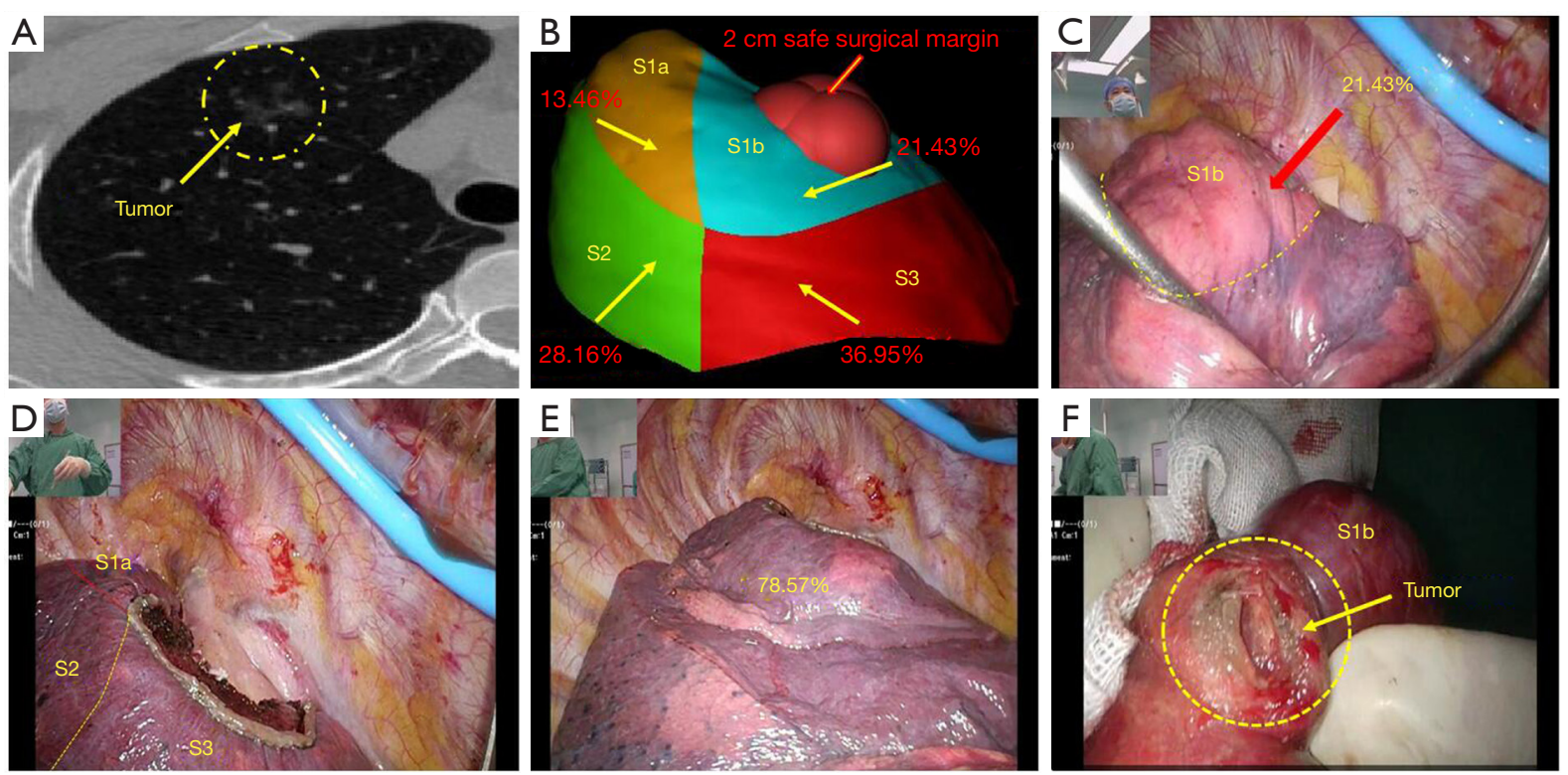

Figure 3 Planning resection region and target lung segment by 3D simulation to evaluate the value of APL. (A) A 13-mm pure GGO nodule at the right upper lobe; (B) $2 \mathrm{~cm}$ safe surgical margin was within RS1b; (C-F) APL with RS1b was performed based on the 3D simulation and only $21.43 \%$ of the right upper lung function was lost. 3D, three-dimensional; APL, anatomical partial lobectomy; GGO, ground-glass opacity; S1, apical segment; S2, posterior segment; S3, anterior segment. 
Table 1 Baseline characteristics of the patients before surgery

\begin{tabular}{lc}
\hline Characteristics & $\mathrm{N}$ \\
\hline Age, years & $33-79$ \\
Range & 53.7 \\
Median & $59 / 97$ \\
Male/female & 38 \\
Active smokers & \\
BMl, kg/m ${ }^{2}$ & $20.1-25.8$ \\
Range & 22.3 \\
Median & \\
Image characteristics & \\
Size, mm & $8-20$ \\
Range & 13.9 \\
Median & 51 \\
Pure GGO & 105 \\
GGO with <50\% solid part & \\
\hline
\end{tabular}

BMI, body mass index; GGO, ground-glass opacity.

segment was removed in a protective bag through the main utility incision and sent for intraoperative frozen section procedure. If this procedure confirmed a minimally invasive adenocarcinoma (MIA) or AIS, systemic hilar and mediastinal lymph node sampling was performed. If the frozen section procedure confirmed an invasive adenocarcinoma (IA), systemic hilar and mediastinal lymph node dissection was performed. Finally, an 8-Fr thoracic catheter connected to the negative pressure drainage bottle was placed in the observation port. Early mobilization out of bed was started at 12 hours postoperatively. The chest tube was removed if there was no air leak, well-inflated lung on chest $\mathrm{X}$-ray, and less than $150 \mathrm{~mL}$ of drainage during the past 24 hours. At 3 months postoperatively, all patients underwent chest CT examination.

\section{Statistical analysis}

All data were expressed as mean \pm standard deviation (SD). The statistical software package of social science software version 23.0 for windows (SPSS, Chicago, IL, USA) was used for statistical analysis. The Student's $t$-test or Wilcoxon test were used to compare quantitative continuous data. $\mathrm{P}$ values less than 0.05 were considered statistically significant.

\section{Results}

The data of 156 patients who underwent 3D interactive quantitative planned VATS APL were collected. The study group included $59(37.8 \%)$ men and 97 (62.2\%) women aged between 33 and 79 (median, 53.7) years. Among these patients, 38 were active smokers. In all patients, the body mass index (BMI) ranged from 20.1 to 25.8 (median, 22.3) $\mathrm{kg} / \mathrm{m}^{2}$ and the lesion diameter was between 8 and 20 (median, 13.9) $\mathrm{mm}$, with $51(32.7 \%)$ lesions having pure GGO. The consolidation ratio of 105 (67.3\%) lesions was $<50 \%$. The patients' characteristics are listed in Table 1. $3 \mathrm{D}$ reconstruction was successful in all patients, facilitating determination of the operation plan according to the simulation results; adequate resection margin distance was determined for all patients. Eighty-eight patients underwent single segmentectomy or subsegmentectomy, while 68 patients underwent combined segmentectomy or subsegmentectomy. VATS APL was performed in every patient successfully, and there were no conversions to thoracotomy or lobectomy. The types of APL procedures are shown in Table 2.

Pathological examination showed that the surgical margins of all patients were sufficient to achieve radical resection. The median surgical margin distance was 2.2 (range, 2.0-2.8) cm. All patients had an R0 complete cancer resection on histology. The histological subtypes of the segmental lesions included 69 cases of MIA, 61 cases of adenocarcinoma, one case of squamous cell carcinoma, 16 cases of AIS, and nine cases of atypical adenomatous hyperplasia (AAH). Among those with AIS or MIA, systemic hilar and mediastinal lymph node sampling was performed in 85 patients. Systemic hilar and mediastinal lymph node dissection were performed in 62 patients among those with adenocarcinoma or squamous cell carcinoma. No patients were identified with postoperative lymph node involvement. The pathological examination characteristics of the patients are shown in Table 3.

The median operation time was 119 (range, 57-245) min and median intraoperative blood loss was 37 (range, 15-247) $\mathrm{mL}$. The median duration of chest tube insertion was 2.3 (range, 1-23) days, and the median length of postoperative hospital stay was 3.7 (range, 3-25) days. The postoperative morbidity rate was $7.1 \%$ (11/156 patients, including five with prolonged air leakage (3-7 days), one with postoperative atelectasis owing to productive cough in chronic bronchitis, one with pneumonia, and four with hemoptysis (3-7 days). All patients who experienced 
Table 2 Types of VATS APL procedures

\begin{tabular}{|c|c|}
\hline Type of APL procedure & $\mathrm{N}$ \\
\hline \multicolumn{2}{|l|}{ Left upper lobe } \\
\hline LS1 + LS2 & 9 \\
\hline LS1 + LS2a & 2 \\
\hline LS1 + LS2a + LS2b & 3 \\
\hline LS1 + LS2c & 1 \\
\hline LS3 & 3 \\
\hline LS3b + LS3c & 6 \\
\hline LS1 + LS2 + LS3 & 7 \\
\hline LS4 + LS5 & 10 \\
\hline LS5 & 3 \\
\hline LS4 + LS5 + LS3a & 3 \\
\hline \multicolumn{2}{|l|}{ Left lower lobe } \\
\hline LS6 & 11 \\
\hline LS6b + LS8a & 3 \\
\hline LS6b + LS8a + LS9a & 1 \\
\hline LS6c + LS10a & 1 \\
\hline LS8 & 3 \\
\hline LS8 + LS9 & 2 \\
\hline LS9 & 3 \\
\hline LS10 & 3 \\
\hline LS9 + LS10 & 3 \\
\hline \multicolumn{2}{|l|}{ Right upper lobe } \\
\hline $\mathrm{RS} 1$ & 9 \\
\hline $\mathrm{RS} 1$ + RS3b & 3 \\
\hline$R S 1 b+R S 3 b$ & 2 \\
\hline $\mathrm{RS} 1+\mathrm{RS} 2$ & 2 \\
\hline $\mathrm{RS} 2$ & 12 \\
\hline $\mathrm{RS} 2 \mathrm{a}+\mathrm{RS} 1 \mathrm{a}$ & 2 \\
\hline$R S 2 b+R S 3 a$ & 6 \\
\hline RS3 & 10 \\
\hline $\mathrm{RS} 1 \mathrm{~b}$ & 3 \\
\hline \multicolumn{2}{|l|}{ Right lower lobe } \\
\hline RS6 & 12 \\
\hline $\mathrm{RS} 6 \mathrm{~b}+\mathrm{RS} 8 \mathrm{a}$ & 3 \\
\hline $\mathrm{RS} 6+\mathrm{RS} 10$ & 1 \\
\hline
\end{tabular}

Table 2 (continued)
Table 2 (continued)

\begin{tabular}{|c|c|}
\hline Type of APL procedure & $\mathrm{N}$ \\
\hline $\mathrm{RS} 7+\mathrm{RS} 8$ & 2 \\
\hline RS8 & 2 \\
\hline RS9 & 2 \\
\hline RS10 & 3 \\
\hline $\mathrm{RS} 9+\mathrm{RS} 10$ & 5 \\
\hline \multicolumn{2}{|c|}{$\begin{array}{l}\text { VATS, video-assisted thoracoscopic surgery; APL, anatomical } \\
\text { partial lobectomy; L, left; S1, apical segment; S2, posterior } \\
\text { segment; S3, anterior segment; LS4, superior lingular segment; } \\
\text { LS5, inferior lingular segment; S6, superior segment; S8, anterior } \\
\text { basal segment; S9, lateral basal segment; S10, posterior basal } \\
\text { segment; R, right; S7, medial basal segment. }\end{array}$} \\
\hline
\end{tabular}

postoperative complications were treated and discharged with no obvious symptoms. There were no cases of perioperative death. During the median postoperative follow-up period of 11 (range, 2-26) months, no tumor recurrence or postoperative death was observed. The operative results of the patients are shown in Table 3.

The operation time during the learning curve of $3 \mathrm{D}$, interactive quantitative planned VATS anatomic segmentectomy is shown in Figure 4. The learning curve showed a tendency towards decreased operation time compared with in the first 30 cases $(\mathrm{P}<0.01)$, and the operation time was stable. Based on these findings, $3 \mathrm{D}$ interactive quantitative planned VATS APL was determined to have a learning curve of 30 cases.

\section{Discussion}

VATS APL is becoming more widely used in clinical practice, and is a skill that thoracic surgeon must master. Compared with lobectomy, APL can preserve more lung function and is suitable for benign diseases and malignant tumors. Regarding malignant tumors, segmental resection is mainly suitable for patients with early lung cancer. Several studies have demonstrated a similar treatment effect between VATS lobectomy and segmentectomy for early lung cancer involving small lesions $(3,4)$. These advantages have garnered increased attention among both thoracic surgeons and patients. However, VATS APL is a significantly more complex procedure than lobectomy. The main reason that this technique is more challenging and demanding is the anatomic complexity. $3 \mathrm{D}$ interactive quantitative surgical planning has demonstrated reliability 
Table 3 Surgical results

\begin{tabular}{|c|c|}
\hline Variables & $\mathrm{N}$ \\
\hline \multicolumn{2}{|l|}{ Operation time, minutes } \\
\hline Range & $57-245$ \\
\hline Median & 119 \\
\hline \multicolumn{2}{|l|}{ Bleeding, $\mathrm{mL}$} \\
\hline Range & $15-247$ \\
\hline Median & 37 \\
\hline \multicolumn{2}{|l|}{ Chest tube duration, days } \\
\hline Range & $1-23$ \\
\hline Median & 2.3 \\
\hline \multicolumn{2}{|c|}{ Postoperative hospital stay, days } \\
\hline Range & $3-25$ \\
\hline Median & 3.7 \\
\hline Conversion to thoracotomy & 0 \\
\hline \multicolumn{2}{|l|}{ Complication } \\
\hline Atelectasis & 1 \\
\hline Air leakage, $>3$ days & 5 \\
\hline Hemoptysis, $>3$ days & 4 \\
\hline Pneumonia & 1 \\
\hline \multicolumn{2}{|l|}{ Pathology } \\
\hline AAH & 9 \\
\hline AIS & 16 \\
\hline MIA & 69 \\
\hline \multicolumn{2}{|l|}{$\mathrm{IA}$} \\
\hline Well-differentiated & 37 \\
\hline Moderately-differentiated & 23 \\
\hline Poorly-differentiated & 1 \\
\hline Squamous cell carcinoma & 1 \\
\hline
\end{tabular}

$\mathrm{AAH}$, atypical adenomatous hyperplasia; AIS, adenocarcinoma in situ; MIA, minimally invasive adenocarcinoma; IA, invasive adenocarcinoma.

in pulmonary surgical planning; therefore, it is believed that $3 \mathrm{D}$ reconstruction could identify segmental structures, reveal anatomic variations, and help locate the pulmonary nodule. Preoperative simulation on 3D images is beneficial to resect target segments accurately while reducing surgical difficulty $(9,10,15)$.

During thoracoscopic APL, in which direct palpation of the pulmonary nodule is not always possible, effective identification of the tiny pulmonary nodule is crucial. 3D reconstruction is convenient for locating the pulmonary nodule and target segment, particularly those located in the deep parenchyma or on the border of adjacent segments. Identification of surgical margins and the APL approach is important, particularly in cases of malignancy, and the surgical margins should be $>2 \mathrm{~cm}$. Preoperative APL simulation using $3 \mathrm{D}$ images enables the surgeon to identify safe surgical margins and perform corresponding segmentectomies, including single subsegmentectomy, single segmentectomy, combined segmentectomy, or combined subsegmentectomy. Anatomic variations of segmental bronchi and vessels are complicated, but 3D reconstruction can clearly reveal the segmental anatomic structure and the variations of bronchi and vessels (16), which can improve both the accuracy and safety of the operation. In fact, to design margin or intersegmental line before operation by using $3 \mathrm{D}$ reconstruction is a critical step in APL. The presented study indicates that the less experienced surgeon had a tendency of shorter operation time when performing APL assisted with preoperative resection simulation using $3 \mathrm{D}$ reconstruction. Based on the $3 \mathrm{D}$ interactive quantitative surgical planning, APL can be performed successfully. It also reduces the difficulty of operation and can be applied in most medical centers. Some experienced surgeons prefer to operate by referring to CT images and actual conditions during the operation. However, for complex pulmonary surgery, this is not the primary trend.

The feasibility of segmentectomy for patients with GGO was discussed by Iwata et al. (17). We consider segmentectomy as a preferred option for such cases before the final results of two ongoing randomized clinical studies $(18,19)$. During our practice, we also performed APL to ensure there is enough surgical margin. The type of APL procedures was consistent with the preoperative planning in all cases. Although five patients developed prolonged air leakage, the median chest tube duration was only 2.3 days. Postoperative morbidity was low $(11 / 156 ; 7.1 \%)$ and postoperative hospital stay was only 3.7 days. There were no perioperative deaths. The extent of lymph node dissection varied in this study, and no patients were identified with lymph node involvement postoperatively. During the median postoperative follow-up period of 11 months, no tumor recurrence or postoperative death was observed, and the results were satisfactory.

The learning curve of VATS APL has not yet been 


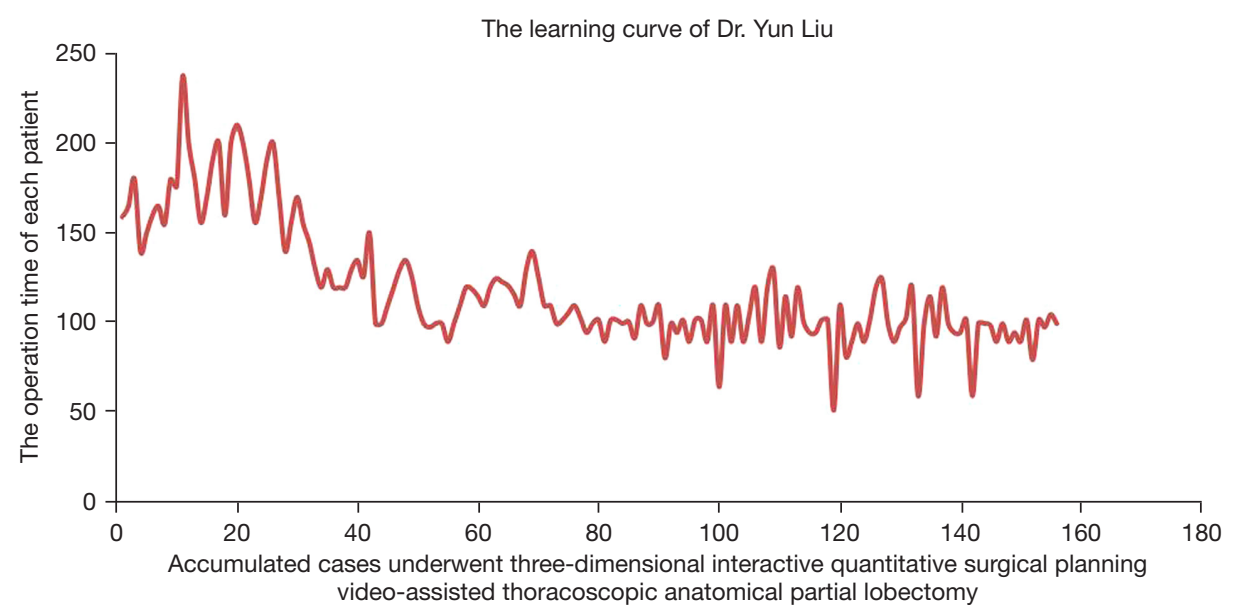

Figure 4 The learning curve of 3D interactive quantitative planned VATS APL. 3D, three-dimensional; VATS, video-assisted thoracoscopic surgery; APL, anatomical partial lobectomy.

elucidated; this study described the learning curve of VATS APL for the first time. Hamada et al. (20) reported on the learning curve for thoracoscopic anatomic segmentectomy, and their data suggested that the inflection point for the learning curve was achieved after 84 cases at their institution, whereas the leading surgeon needed only 32 cases to achieve this level of competence. In the current study, we found that the 3D interactive quantitative planned VATS APL could be mastered after 30 cases. Kato et al. (11) reported the use of 3D CT images for surgical simulation during anatomic thoracoscopic pulmonary segmentectomy and the effectiveness of this technique. These data should be used by training programs and credentials committees for establishing standards to ascertain good outcomes in thoracic surgery. The results showed the merits of $3 \mathrm{D}$ reconstruction in VATS APL, and that $3 \mathrm{D}$ interactive quantitative surgical planning may enable accurate identification of GGO lesions and illustrate the variation pattern of the segmental bronchi and vessels $(13,21,22)$. A 3D digital anatomy database for patients undergoing accurate VATS APL is necessary for larger data analysis in the era of precision medicine and artificial intelligence.

APL is a surgical skill that every thoracic surgeon urgently needs to master, $3 \mathrm{D}$ interactive quantitative surgical planning reduced the difficulties related to APL. We believe that even an inexperienced surgeon using $3 \mathrm{D}$ reconstruction can perform thoracoscopic APL, with a learning curve of 30 cases and with acceptable safety and complications. We suggest that young thoracic surgeons should master 3D reconstruction technology, and complete
$3 \mathrm{D}$ reconstruction before surgery, which is conducive to doctors to master surgical technology and improve their ability to read CT images.

\section{Acknowledgments}

Funding: This study was supported by the Medical and Health Research Program (A20-2-015), Science \& Technology Bureau of Yichang.

\section{Footnote}

Reporting Checklist: The authors have completed the STROBE reporting checklist. Available at https://dx.doi. org/10.21037/jtd-21-1578

Data Sharing Statement: Available at https://dx.doi. org/10.21037/jtd-21-1578

Conflicts of Interest: All authors have completed the ICMJE uniform disclosure form (available at https://dx.doi. org/10.21037/jtd-21-1578). The authors have no conflicts of interest to declare.

Ethical Statement: The authors are accountable for all aspects of the work in ensuring that questions related to the accuracy or integrity of any part of the work are appropriately investigated and resolved. The study was conducted in accordance with the Declaration of Helsinki (as revised in 2013). The protocol of this study was approved by 
the institutional review board of Yichang Central People's Hospital (No. HEC-KYJJ-2018-601-01). Informed consent was obtained from the patients before surgery.

Open Access Statement: This is an Open Access article distributed in accordance with the Creative Commons Attribution-NonCommercial-NoDerivs 4.0 International License (CC BY-NC-ND 4.0), which permits the noncommercial replication and distribution of the article with the strict proviso that no changes or edits are made and the original work is properly cited (including links to both the formal publication through the relevant DOI and the license). See: https://creativecommons.org/licenses/by-nc-nd/4.0/.

\section{References}

1. Wisnivesky JP, Henschke CI, Swanson S, et al. Limited resection for the treatment of patients with stage IA lung cancer. Ann Surg 2010;251:550-4.

2. Shapiro M, Weiser TS, Wisnivesky JP, et al. Thoracoscopic segmentectomy compares favorably with thoracoscopic lobectomy for patients with small stage I lung cancer. J Thorac Cardiovasc Surg 2009;137:1388-93.

3. Dai C, Shen J, Ren Y, et al. Choice of surgical procedure for patients with non-small-cell lung cancer $\leq 1 \mathrm{~cm}$ or $>1$ to $2 \mathrm{~cm}$ among lobectomy, segmentectomy, and wedge resection: a population-based study. J Clin Oncol 2016;34:3175-82.

4. Zhao X, Qian L, Luo Q, et al. Segmentectomy as a safe and equally effective surgical option under complete videoassisted thoracic surgery for patients of stage I non-small cell lung cancer. J Cardiothorac Surg 2013;8:116.

5. Gao S, Qiu B, Li F, et al. Comparison of thoracoscopic anatomical partial-lobectomy and thoracoscopic lobectomy on the patients with pT1aN0M0 peripheral non-small cell lung cancer. Zhonghua Wai Ke Za Zhi 2015;53:727-30.

6. Qiu B, Ji Y, He H, et al. Three-dimensional reconstruction/personalized three-dimensional printed model for thoracoscopic anatomical partial-lobectomy in stage I lung cancer: a retrospective study. Transl Lung Cancer Res 2020;9:1235-46.

7. Ettinger DS, Akerley W, Bepler G, et al. Non-small cell lung cancer. J Natl Compr Canc Netw 2010;8:740-801.

8. Shimizu K, Nagashima T, Ohtaki Y, et al. Analysis of the variation pattern in right upper pulmonary veins and establishment of simplified vein models for anatomical segmentectomy. Gen Thorac Cardiovasc Surg 2016;64:604-11.
9. Iwano S, Yokoi K, Taniguchi T, et al. Planning of segmentectomy using three-dimensional computed tomography angiography with a virtual safety margin: technique and initial experience. Lung Cancer 2013;81:410-5.

10. Chan EG, Landreneau JR, Schuchert MJ, et al. Preoperative (3-dimensional) computed tomography lung reconstruction before anatomic segmentectomy or lobectomy for stage I non-small cell lung cancer. J Thorac Cardiovasc Surg 2015;150:523-8.

11. Kato H, Oizumi H, Suzuki J, et al. Thoracoscopic anatomical lung segmentectomy using $3 \mathrm{D}$ computed tomography simulation without tumour markings for nonpalpable and non-visualized small lung nodules. Interact Cardiovasc Thorac Surg 2017;25:434-41.

12. Murgitroyd E, Madurska M, Gonzalez J, et al. 3D digital anatomy modelling - Practical or pretty? Surgeon 2015;13:177-80.

13. Liu C, Liao H, Guo C, et al. Single-direction thoracoscopic basal segmentectomy. J Thorac Cardiovasc Surg 2020;160:1586-94.

14. Liu Y, Zhang S, Che Z. Three-dimensional interactive quantitative surgical planning inferior pulmonary ligament approach VATS right S9+10 segmentectomy. Curr Chall Thorac Surg 2021. doi: 10.21037/ccts-2019-filsc-07-m01.

15. Wu WB, Xu XF, Wen W, et al. Three-dimensional computed tomography bronchography and angiography in the preoperative evaluation of thoracoscopic segmentectomy and subsegmentectomy. J Thorac Dis 2016;8:S710-5.

16. Nakashima S, Watanabe A, Ogura K, et al. Advantages of preoperative three-dimensional contrast-enhanced computed tomography for anomalous pulmonary artery in video-assisted thoracoscopic segmentectomy. Eur J Cardiothorac Surg 2010;38:388.

17. Iwata H, Shirahashi K, Mizuno Y, et al. Feasibility of segmental resection in non-small-cell lung cancer with ground-glass opacity. Eur J Cardiothorac Surg 2014;46:375-9; discussion 379.

18. Suzuki K, Saji H, Aokage K, et al. Comparison of pulmonary segmentectomy and lobectomy: safety results of a randomized trial. J Thorac Cardiovasc Surg 2019;158:895-907.

19. Altorki NK, Wang X, Wigle D, et al. Perioperative mortality and morbidity after sublobar versus lobar resection for early-stage non-small-cell lung cancer: post-hoc analysis of an international, randomised, phase 3 trial (CALGB/Alliance 140503). Lancet Respir Med 
2018;6:915-24.

20. Hamada A, Oizumi H, Kato H, et al. Learning curve for port-access thoracoscopic anatomic lung segmentectomy. J Thorac Cardiovasc Surg 2018;156:1995-2003.

21. Xue L, Fan H, Shi W, et al. Preoperative 3-dimensional computed tomography lung simulation before videoassisted thoracoscopic anatomic segmentectomy for ground glass opacity in lung. J Thorac Dis

Cite this article as: Liu Y, Zhang S, Liu C, Sun L, Yan M. Three-dimensional reconstruction facilitates thoracoscopic anatomical partial lobectomy by an inexperienced surgeon: a single-institution retrospective review. J Thorac Dis 2021;13(10):5986-5995. doi: 10.21037/jtd-21-1578
2018;10:6598-605.

22. Liu Y, Qiu B, Zhang S, et al. A simplified model for determining the cutting plane during thoracoscopic anatomical partial lobectomy of the right lower lobe. Transl Lung Cancer Res 2021;10:3203-12.

(English Language Editor: A. Kassem) 